\title{
Impact of Implementing Graphing Calculators on College Algebra Students' Performance, Satisfaction, and Motivation
}

\author{
Manuel Rodriguez \\ Northcentral University \\ San Diego, California
}

\begin{abstract}
The purpose of this study was to investigate the impact graphing calculators had on students' performance, satisfaction, and motivation. A quasi-experiment was performed on an experimental group $(n=33)$ and a control group $(n=42)$ comprised of college algebra students from Miami Dade College, to compare their final grades. Experimental group participants were also surveyed about their satisfaction and motivation with using graphing calculators. Results of independent samples $t$ tests revealed insignificant difference between the control and experimental groups' performance $(\mathrm{p}=.560)$, but a significant difference was between the two groups' motivation $(p=.003)$ and satisfaction $(\mathrm{p}=.018)$. These results suggest that graphing calculators may play important roles other than simply enhancing student performance, which then opens the door for future investigations into their use in mathematical education.
\end{abstract}

Keywords: College Algebra; Graphing Calculators; Technology; Mathematical Education.

\section{Introduction}

The plight of an algebra instructor in helping students visualize and comprehend the abstract functions and processes involved in the subject matter is deep-seated in almost any classroom, especially in the college level. Considering how this is the first compulsory college level math course for undergraduate studies, it is disheartening how many students, approximately $70 \%$ in the U.S., fail in this course (Dewey et al., 2009). Some instructors, however, have begun exploring technological advancements over the years to find a suitable tool to make algebra more interesting and comprehensible. One of such tools is the graphing calculator, which has been found to enhance learning as students were able to graph, visualize, and solve equations on their graphing calculators simultaneously with their instructors (Leng, 2011). Unfortunately, the 
use of graphing calculators in college algebra classes has been underappreciated and understudied (King \& Robinson, 2012; Martin, 2008).

Two graphing calculators, the TI-83 Plus or the TI-84 Plus from Texas Instruments (TI), are considered the most user-friendly models. Over the past 15 years, these two TI calculator models have evolved in terms of their graphing capabilities, additional memory capacity, and faster microprocessors to display and calculate commands and data values. Yet, their basic commands have remained standard and easy to manipulate, which means that the majority of college students can understand their operation and improve their mathematical knowledge by using the TI calculator technology (King \& Robinson, 2012). These two models are then potential tools that are easy to navigate and may serve to engage students in algebra classes.

Some instructors, however, believe that graphing calculators may be deleterious as students may use them without proper understanding, creating a possible avenue for cheating their way through equations (King \& Robinson, 2012). They believe that students may arrive at correct answers with the use of graphing calculators, without truly understanding the solutions behind them (Martin, 2008). Martin (2008) then pointed out that this type of thinking may be obsolete and elitist, and that graphing calculators may be used help students understand equations, not simply solve them. Cedillo (2001) likened the algebraic code used in graphing calculators to language, which meant that students must understand the equation and think of solutions before translating it into the language of algebraic code to be inputted in the calculator. This places the graphing calculator in the position of translator, instead of simply a provider of answers, allowing students to visualize and compare mathematic calculations not just from an algebraic point of view, but also from a graphical or visual one (Cedillo, 2001).The dual lens provided by graphing calculators entails an ever deeper understanding of the mathematic calculations and functions, in conjunction with the expert guidance of a math instructor (Handal, et al., 2011).

The purpose of this research project was to investigate the impact graphing calculators have on college students' final grade, along with their motivation and satisfaction with using the graphing calculators, after completing a required college algebra course. As Martin (2008) asserted, graphing calculators are taking on an important role in teaching mathematics, especially at the secondary and college levels. It is, therefore, expected that the use of graphing calculators will expand the comprehension of algebraic equations and functions, and keep students more motivated and satisfied with their lessons.

Three research questions were raised along with their corresponding hypotheses:

RQ1.To what extent, if any, does a difference exist in the final grades of students in a college algebra course among students who use a graphing calculator compared with those who do not? 
$\mathrm{H} 1_{0}$.There was no significant difference in the final grades of students in a college algebra course among students who used a graphing calculator compared with those who did not.

$\mathrm{H} 1_{\mathrm{a}}$.There was a significant difference in the final grades of students in a college algebra course among students who used a graphing calculator compared with those who did not.

RQ2. To what extent, if any, does a difference exist in students' motivation with their performance in a college algebra course among students who use a graphing calculator compared with those who do not?

$\mathrm{H} 20$. There was no significant difference in students' motivation with their performance in a college algebra course among students who used a graphing calculator compared with those who did not.

$\mathrm{H} 2$. There was a significant difference in students' motivation with their performance in a college algebra course among students who used a graphing calculator compared with those who did not.

RQ3.To what extent, if any, does a difference exist in students' satisfaction in a college algebra course among students who use a graphing calculator compared with those who do not?

$\mathrm{H} 3_{0}$.There was no significant difference in students' satisfaction in a college algebra course among students who used a graphing calculator compared with those who did not.

$\mathrm{H}_{\mathrm{a}}$.There was a significant difference in students' satisfaction in a college algebra course among students who used a graphing calculator compared with those who did not.

\section{Theoretical Framework}

This study employed two theories as its framework. The first is the constructivist theory, which purports that individuals construct ideas out of their experiences in their own unique ways, which places the student as the center of their own learning (Colburn, 2007; Simpson, 2002). This theory of learning comports with the use of graphing calculators as this tool assists in visualizing challenging and abstract concepts in college algebra such as transformation of functions, allowing for a more in-depth physical experience from which students may form their constructs. With the graphing calculator, the majority of the students are compelled to take an active role during the lectures. The students' "hands-on experience" facilitates a better understanding of the topics while using this technological tool (Brown, 2010). When instructors teach a class such as college algebra from the student's own perspective using the graphing calculator, consistent with the constructivist approach, learning becomes a personal matter (Simpson, 2002).

Constructivism theory allows for flexibility on the part of the instructor, as it is not a set methodology, rather, it is an epistemology that simply explains how learners gain knowledge (Simpson, 2002). Divergent techniques and teaching methods may be applied in constructivism, however, it is ultimately the guidance of the math professor in conjunction with the students' motivation to learn which serve as the main ingredients that create a context for learning and understanding of mathematics in a more efficient and meaningful way (Burns, 
2005). This creates a balance between student-centered and professor-centered instruction. Moreover, improvements in students' levels of motivation and satisfaction with mathematics would also be in line with the theory of constructivism, as the cornerstone of this theory is that students are prioritized during the entire learning process, which includes the development of their motivation and satisfaction.

The second theoretical framework for this study was the technology-assisted instruction theory, which purports that technological advancements are highly advantageous in education, especially for contexts that require abstract conceptualization and reflective observation (Hui et al., 2008; Paquette, 2014). This straightforward theory supports the use of all technologies that provide clearer and deeper understanding of concepts and topics. Past researchers who have utilized this theory have found that the use of different kinds of technology enhances student satisfaction and motivation to participate and learn (Harris, Al-Bataineh, \& Al-Bataineh, 2016; Hui et al., 2008; Olsen \& Chernobilsky, 2016). These two theories display how the use of graphing calculators, a piece of technology that provides "hands-on" experience, may prove beneficial for college algebra students.

\section{Literature Review}

Aside from the two theories that supported this study, past researchers have also specifically examined the use of technology such as graphing calculators in different mathematics classes. The lack of technology usage in the classroom has proven to be detrimental to the modern classroom, especially considering the recent breakthrough of high stakes testing (Bowman, 2018). This finding is unpropitious considering how technology has advanced over the past decades, and provided multiple opportunities for improved education.

Redesigned classes which included technology-use such as lab components, sophisticated educational softwares, multimedia tools, 3D technology, and virtual manipulatives, have been found to enhance mathematics education and improve students' grades (Foshee, Elliott, \& Atkinson, 2016; Francis, 2017; Kwon, 2017; Porter, Ofodile, \& Carthon, 2015). These redesigned classes were compared to traditional classes with no technological usage, and the results all supported the hypothesis that these redesigned classes produced better passing rates and higher levels of achievement for students (Francis, 2017; Porter et al., 2015). Furthermore, students who used educational technology reported higher confidence and self-efficacy in beliefs of their own competence in math (Foshee et al., 2016; Francis, 2017; Kwon, 2017). Students' motivation regarding technology also increased, especially for students with learning disabilities who had trouble with traditional methods of learning (Francis, 2017).

The specific use of graphing calculators has also been studied with promising results. Abu-Naja's (2010) study revealed how high school students from Israel who used graphing calculators attained a better understanding of positive and negative mathematical functions than those who did not. This result expedited the movement in Israel allowing students to use graphing calculators in their 
algebra classes. Graphing calculators also significantly improved students' understanding of and achievement in geometry (Kandemir \& Demirbağ-Keskin, 2019). A study in Malaysia also led to the conclusion that graphing calculators, more than scientific calculators, allowed students to gain a better understanding of the course material and perform better in examinations (Tan \& Tan, 2015). Also in Malaysia, Parrot and Leong's (2018a) study displayed how the graphing calculators' split-screen mode allowed students to view multiple representations of an equation, thereby enhancing their understanding of the equation. Students also expressed how its use made learning mathematics easier and more interesting (Tan \& Tan, 2015).

Even in related subjects such as calculus, students immensely benefited from using graphing calculators, specifically the TI-Nspire model (Parrot \& Leong, $2018 \mathrm{~b})$. The students also reported increased motivation, interest, and selfconfidence, as graphing calculators allowed them to visualize challenging graphs of mathematical functions and to efficiently analyze abstract mathematical ideas. Furthermore, students indicated that the TI-Nspire changed their beliefs about calculus and made it more fun (Parrot \& Leong, 2018b)). Parrot and Leong's (2018b) study displayed the numerous benefits of using graphing calculators, with students reporting little to no disadvantages. Even though students had some difficulty adapting to the new technology, they eventually grew more proficient within one to two months (Parrot \& Leong, 2018b). The student-centeredness of using graphing calculators was emphasized in Crawford et al.'s (2018) study, as students were allowed more creativity in solving problems by themselves. The use of technology also allowed them to easily recognize and correct their errors (Crawford et al., 2018).

Unfortunately, in the U.S., even with the recommendations of the National Council of Teachers of Mathematics (NCTM), secondary teachers still have reservations on using graphing calculators in class and during exams (Karadeniz \& Thompson, 2017). Teachers reported that the use of some graphing calculators, particularly those with Computer Algebra System (CAS), is not allowed in most colleges and in the American College Testing (ACT) exam; hence they prefer to prepare their students using more traditional methods (Karadeniz \& Thompson, 2017). On the other hand, some state exams actually require the use of graphing calculators (Nzuki, 2016). Nzuki (2016) then emphasized the contextual factors, such as college preparation and student socio-economic status (SES), which teachers considered regarding the use of graphing calculators. The author reported how student from low SES backgrounds may not have a strong enough mathematical foundation, and end up using the graphing calculator to simply arrive at answers instead of using it to understand the problems (Nzuki, 2016). As there is no nation-wide mandate requiring the use of graphing calculators, teachers may not actually be fully equipped with skills and knowledge regarding graphing calculators (Farmer, 2016). With today's fast-paced and dynamic technological environment, however, students and teacher alike may need to adapt and explore these technological tools that may be beneficial for their education. 
Indeed, meta-analyses have provided results that support the use of graphing calculators in education since the early 2000s (Barton, 2001; Ellington, 2006). Barton's (2001) meta-analysis focused on overall student achievement using 46 studies that had control and experimental groups. Of the 46 studies, 29 of them concluded that the experimental group using graphing calculators had higher overall achievement than the control group who did not use these calculators; only one study found that overall achievement was better in the control group, and 13 found no significant difference in achievement between the two groups. Ellington's (2006) meta-analysis likewise displayed how graphing calculators may be beneficial when used for both instruction and assessment. Students' attitudes towards mathematics also improved with the use of graphing calculators, revealing yet another benefit of their use (Ellington, 2006). With the results of these studies, it is perplexing why schools and instructors do not attempt to utilize graphing calculators in their mathematics classes. This current study aimed to provide more evidence to support the use of this potentially valuable tool.

\section{Methods}

This current study employed the quasi-experimental design to determine the impact of graphing calculators on college algebra students' performance, satisfaction, and motivation. The methodology was guided by the two theoretical frameworks, constructivism (Colburn, 2007; Simpson, 2002) and technology-assisted instruction (Hui, et al., 2008; Paquette, 2014). The inclusion criteria required only that students be enrolled in one of the two algebra classes in the fall/spring semester at Miami Dade College. No restrictions were set for their age, gender, majors, or any other variable. The first class, with 42 students, served as the control group, while the second class, with 33 students, comprised the experimental group. Both these classes lasted the standard college semester of 16 weeks, under similar conditions, with the same instructor. Many topics were covered including graphing and solving different types of equations, functions, and transformations. The graphing calculators were used every week for the experimental group. The differentiating factor for the experimental group was the mandatory use of graphing calculators. TI-84 Plus and TI-83 Plus models were used, as they appear to be user-friendly models.

As the design used was quasi-experimental, purposive sampling was used to select the most eligible classes. Students were informed about the general nature of the study and that they could withdraw early or drop the course later in the semester. They were also advised of the option to participate or not without adverse effects on their course grades. There were no known risks to participants, and all participants were provided with a written explanation of the study at the start, with the assurance that their final course grade was in no way linked to their participation in the study. No payment or compensation was given to any participant at any point of the study. The study also acquired approval from both the Institutional Review Board (IRB) of Northcentral University (NCU) and from the university where the study was conducted. Confidentiality of all participants was maintained during, and after the study. After the signing of informed consent, the quasi-experiment was under way. 
Participants' final grades were collected from both groups at the end of the term with a grade scale of 0 to 100 points. The final exam included 30 multiple choice items worth 3.33 points each. Data on students' degree of motivation and satisfaction when using the graphing calculator in class was also collected. This was important since math professors could better understand as well as discover in what areas the student faced more challenges and difficulties.

The satisfaction and motivation scales used were based on Kahveci's (2010) adaptation of Fennema and Sherman's Mathematics Attitude Scales (1976). The original 57-item scale was pared down and adapted to the use of the graphing calculator, instead of the use of technology generally in the classroom. Eight statements that specifically measured motivation, as well as seven statements that specifically measured satisfaction, were used. Both scales made use of a fivepoint Likert scale, from "strongly agree" to "strongly disagree." No reliability value was established for the seven satisfaction statements; it is still reliable even if it is within the lower range of Cronbach's alpha values, as low as .777, as established by Kahveci (2010). The briefness and simplicity of the questionnaires contributed to the high response rate. The instruments mentioned above measured the three dependent variables of the study, namely: final grades; level of satisfaction; and level of motivation. The independent variable, graphing calculator variable, comprised of two variables, which simple described whether or not students used graphing calculators in class.

Data on the two groups were collected, and an independent samples t-test was conducted for the differences in terms of the grade differences between final and first exams. A mixed model ANOVA was also conducted using first and final exam scores as separate repeated measures variables and group assignment as a covariate to measure within subject significance. Independent samples $t$ tests were also used to analyze the data for level of motivation and level of satisfaction.

\section{Findings}

A total of 75 participants were initially selected for the study, with $42(56 \%)$ in the control group and $33(44 \%)$ in the experimental group. The participants were purposively selected as two college algebra classes in Miami Dade College. Table 1 presents the gender distribution of all the participants. Majority of the participants were females $(42 \%)$.

Table 1. Demographic Characteristics of Participants $(N=75)$

\begin{tabular}{llll}
\hline & & Frequency & Percent \\
\hline \multirow{2}{*}{ Gender } & Male & 33 & $44 \%$ \\
& Female & 42 & $56 \%$ \\
\hline
\end{tabular}

Table 2 presents the descriptive statistics for participants' age. As it was an optional item, 10 participants chose not to disclose their age. Of the 65 participants who answered the age question, the youngest subject was 18 and the oldest was 43 years old. The age variable was slightly skewed positively because the majority of the participants were centered around the age of 19 and 
only four participants were above 29 years old. Since age was not a target variable for the analyses, no adjustment was made to handle the outliers.

Table 2. Descriptive Statistics for the Age of Participants $(N=65)$

\begin{tabular}{ccllllc}
\hline & & Minimum & Maximum & Mean & $\begin{array}{l}\text { Std. } \\
\text { deviation }\end{array}$ & Skewedness \\
\hline Age & 65 & 18.0 & 43.0 & 21.092 & 4.6190 & 2.890 \\
\hline
\end{tabular}

Out of the 75 participants, only 70 were able to complete the whole course and were considered for data analysis. The five students who did not complete the course were then removed. Table 3 presents the summary of the scores for the first and final exams for each group.

Table 3. Descriptive Statistics for Exam Scores Categorized by Group Assignments $(N=70)$

\begin{tabular}{llll}
\hline & & First Exam & Final Exam \\
\hline Control Group & Mean & 77.368 & 73.632 \\
& $\mathrm{~N}$ & 38 & 38 \\
& Std. Deviation & 15.8001 & 17.8104 \\
& Minimum & 35.0 & 23.0 \\
& Maximum & 100.0 & 100.0 \\
Experimental Group & Skewedness & -.690 & -.892 \\
& Mean & 76.563 & 75.031 \\
& $\mathrm{~N}$ & 32 & 32 \\
& Std. Deviation & 19.9773 & 23.2760 \\
& Minimum & 30.0 & 27.0 \\
& Maximum & 100.0 & 100.0 \\
& Skewedness & -.744 & -.833 \\
\hline
\end{tabular}

In answer to RQ1, Table 4 presents the results of the independent samples t test conducted for the differences in terms of the grade differences between final and first exams. Based on the results, there was insufficient evidence to reject the null hypothesis and conclude that there was a statistically significant grade difference between control and experimental groups $(t=-.58$, $p=.560)$.

Table 4. Independent Samples t-Test for Differences between Control and Experimental Groups $(N=70)$

\begin{tabular}{|c|c|c|c|c|c|c|c|c|c|c|}
\hline & \multirow{2}{*}{\multicolumn{2}{|c|}{ Levene's Test }} & \multicolumn{7}{|c|}{ t-test for equality of means } \\
\hline & & & & \multirow[b]{2}{*}{$\mathrm{t}$} & \multirow[b]{2}{*}{ Df } & \multirow[b]{2}{*}{ Sig. } & \multirow{2}{*}{$\begin{array}{l}\text { Mean } \\
\text { Diff }\end{array}$} & \multirow[b]{2}{*}{ S.E. diff } & \multirow{2}{*}{\multicolumn{2}{|c|}{$\begin{array}{l}\text { 95\% CI Diff } \\
\text { lower upper }\end{array}$}} \\
\hline & & $\mathrm{F}$ & Sig. & & & & & & & \\
\hline $\begin{array}{l}\text { Score } \\
\text { Diff }\end{array}$ & $\begin{array}{l}\text { Equal } \\
\text { variances } \\
\text { assumed }\end{array}$ & .20 & .65 & -.58 & 68 & .560 & -2.20 & 3.77 & -9.74 & 5.33 \\
\hline & $\begin{array}{l}\text { Equal } \\
\text { variances } \\
\text { not assumed }\end{array}$ & & & -.58 & 66.85 & .560 & -2.20 & 3.76 & -9.72 & 5.31 \\
\hline
\end{tabular}

The mixed model ANOVA conducted using first and final exam scores as separate repeated measures variables and group assignment as a covariate revealed no within-subjects effects between first and final scores of the students 
across treatment conditions. Table 5 presents these results. Furthermore, the interaction between treatment conditions and time difference also was not significant. It can be concluded that the results were not significant for research question 1 - the use of graphing calculators did not impact the students' test scores, and therefore, the null hypothesis was not rejected.

Table 5. Within-Subject Effects for Both Time and Group Assignment $(\mathrm{N}=70)$

\begin{tabular}{lllllll}
\hline \multirow{2}{*}{ Source } & & \multicolumn{2}{l}{ Type III Sum } & & & \\
\hline Time & of Squares & Df & Mean Square & F & Sig. \\
& Gphericity Assumed & 241.05 & 1 & 241.05 & 1.942 & .16 \\
& Greenhouse-Geisser & 241.05 & 1.00 & 241.05 & 1.942 & .16 \\
Time * Exp_Ctrl & Huynh-Feldt & 241.05 & 1.00 & 241.05 & 1.942 & .16 \\
& Lower-bound & 241.05 & 1.00 & 241.05 & 1.942 & .16 \\
& Gphericity Assumed & 42.25 & 1 & 42.25 & .34 & .56 \\
& Greenhouse-Geisser & 42.25 & 1.00 & 42.25 & .34 & .56 \\
& Huynh-Feldt & 42.25 & 1.00 & 42.25 & .34 & .56 \\
& Lower-bound & 42.25 & 1.00 & 42.25 & .34 & .56 \\
& Sphericity Assumed & 8438.66 & 68 & 124.09 & & \\
& Greenhouse-Geisser & 8438.66 & 68.00 & 124.09 & & \\
& Huynh-Feldt & 8438.66 & 68.00 & 124.09 & & \\
& Lower-bound & 8438.66 & 68.00 & 124.09 & & \\
\hline
\end{tabular}

RQ2 examined the differences in terms of motivation scores between participants who received the version of class that used graphing calculator and those who did not. The descriptive statistics in Table 6 showed that there were 69 participants who had valid responses to this construct, and of those, the control group scored a mean of 31.59 and the experimental group scored a mean of 35.09 out of a total possible score of 40 .

Table 6. Descriptive Statistics for Motivation Scores Categorized by Group Assignments ( $N=$ 69)

\begin{tabular}{|c|c|c|c|c|c|}
\hline & & $\mathrm{N}$ & Mean & Std. Deviation & Std. Error Mean \\
\hline Total & Cor & 37 & 31.59 & 3.616 & .594 \\
\hline Motivation & Experimental Group & 32 & 35.09 & 5.743 & 1.015 \\
\hline
\end{tabular}

The results of the independent samples t-test are shown in Table 7. According to the analysis with assumed equal variances, the difference in terms of motivation scores after completing the course between control and experimental groups was significant ( $\mathrm{t}=-3.07, \mathrm{p}=.003)$. Based on the results, there was sufficient evidence to reject the null hypothesis. The negative $t$ value indicated that group 2 in the model, which is the experimental group had a higher motivation score overall. 
Table 7. Independent Samples t-Test Results for Difference of Motivation Scores between Control and Experimental Groups $(N=69)$

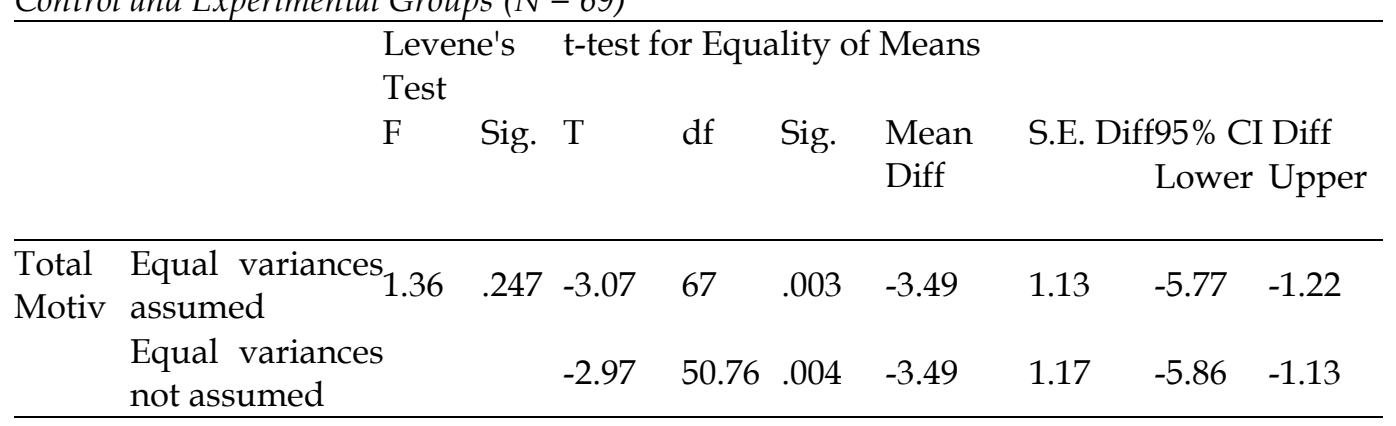

RQ3 examined the differences in terms of satisfaction scores between participants who received the version of class that used graphing calculator and those who did not. The descriptive statistics in Table 8 showed that, similar to the previous question, there were 69 participants who had valid responses to this construct. Of those, the control group scored a mean of 27.94 and the experimental group scored a mean of 31.03 out of a total possible score of 40 .

Table 8. Descriptive Statistics for Satisfaction Scores Categorized by Group Assignment ( $N=$ 69)

\begin{tabular}{|c|c|c|c|c|}
\hline & $\mathrm{N}$ & Mean & Std. Deviation & Std. Error Mean \\
\hline Control Group & 37 & 27.94 & 4.701 & .772 \\
\hline Satisfaction Experimental Group & 32 & 31.03 & 5.833 & 1.031 \\
\hline
\end{tabular}

The independent samples t-test for RQ3, as presented in Table 9, revealed that there was a significant difference between the control and experimental groups as well $(\mathrm{t}=-2.43, \mathrm{p}=.018)$. There was sufficient evidence to reject the null hypothesis. Once again, the t-test was negative, which indicates that group 2 the experimental group had a higher mean satisfaction score when compared with group 1, which was the control group.

Table 9. Independent Samples t-Test Results for Difference of Satisfaction Scores Between Control and Experimental Groups $(N=69)$

\begin{tabular}{|c|c|c|c|c|c|c|c|c|c|c|}
\hline & \multicolumn{9}{|c|}{ Levene's Testt-test for Equality of Means } \\
\hline & & $\mathrm{F}$ & Sig. & $\mathrm{T}$ & $\mathrm{df}$ & Sig. & Mean & ffS.E. [ & $\begin{array}{r}\text { ff } 95 \% \mathrm{Cl} \\
\text { Lower }\end{array}$ & $\begin{array}{l}\text { Diff } \\
\text { Upper }\end{array}$ \\
\hline $\begin{array}{l}\text { Total } \\
\text { Sat }\end{array}$ & $\begin{array}{l}\text { Equal } \\
\text { variances } \\
\text { assumed }\end{array}$ & .227 & .635 & -2.43 & 67 & .018 & -3.08 & 1.26 & -5.61 & -.55 \\
\hline & $\begin{array}{l}\text { Equal } \\
\text { variances } \\
\text { not assumed }\end{array}$ & & & -2.39 & 59.45 & .020 & -3.08 & 1.28 & -5.66 & -.50 \\
\hline
\end{tabular}

\section{Implications}

The findings described above implied that students who did and did not use graphing calculators in algebra courses perform at par with each other. Students who did not use graphing calculators still appeared capable of answering complex mathematical questions. However, the findings also revealed that students who used graphing calculators were likely to be more motivated and 
more satisfied with their college algebra course in the end than those without, which means the calculators' value cannot be easily discounted or rejected. This finding also furthers the theories of constructivism and technology-assisted instruction, as graphing calculators, a technological tool for hands-on learning, made learning a personal matter for the student, leading to higher motivation and satisfaction (Simspon, 2002).

This study's findings on level of satisfaction and motivation after using technological tools, such as graphing calculators, in class are in line with past studies that have supported their use (Parrot \& Leong, 2018b; Tan \& Tan, 2015). Motivation and satisfaction were found to be good indicators of positive learning experiences, not just scores. For instance, Parrot and Leong's (2018b) study revealed that those who used graphing calculator had a better learning experience and performance because they were able to perform more advanced tasks with ease, and it made learning calculus more interesting. This, along with the current study's findings, presents a multi-dimensional purpose of graphing calculators in mathematical education.

\section{Limitations}

Time was a capricious element in this study, as it took place in a regular school semester. It could have been either too long or too short to determine whether a graphing calculator itself was the leading cause of the performance, satisfaction, and motivation of the students. Within this time, multiple factors could have already affected the dependent variables, regardless of graphing calculators use. On the other hand, if the time had been longer, then the students might have gained a better understanding of using the graphing calculators, and the results might have been different. The non-random sampling may also be a factor. Student characteristics may have differed for each group, which might have affected the results. Moreover, the control group had a bigger size than the experimental group of 10 more students, so it was possible that the results were impacted by group size. As the study was conducted in a single institution, results may not be generalizable to other populations. Other factors that were not examined may have also affected the results, such as gender, age, race, and major. Experimenter bias was also possible, even if measures were taken to avoid it, as the researcher was the instructor of these classes.

\section{Recommendations}

Recommendations for practice may be gathered from this study's results. Graphing calculators' motivating effect may guide program developers who struggle with retention. The student retention dilemma has plagued colleges and universities alike. Satisfaction and motivation can have a meaningful impact on retention and performance of students. By seeing the value of graphing calculators in facilitating the satisfaction and motivation of students, if not their performance alone, schools could improve the retention rates of students, especially those who grapple with understanding mathematics and abstract concepts. 
Several recommendations can also be made for future researchers. Future researchers can address these limitations or take other relevant directions based on the findings of the current study. Increased sample size, more groups, insertion of possible mediating or moderating factors, and a qualitative element may be rendered by future researchers to add value to this study's findings. Future research can also take one step further and look at the effects of the graphing calculator on students' performance on other mathematics courses, post-algebra.

\section{Conclusion}

The results of this study revealed that although student performance did not differ between students who used and did not use graphing calculators, the difference in their levels of satisfaction and motivation displayed how the tool may be of value in other ways. It also provided further evidence to the theory of construction, which claims hands-on experience in teaching and the learning process cannot be undervalued. The use of graphing calculators can make the hands-on experience more fruitful and focused. It is critical that schools and teachers start seeing the value of graphing calculators without qualms now, primarily since their usage no longer just affects performance or ability, but also satisfaction and motivation.

\section{References}

Abu-Naja, M. (2010). The influence of graphic calculators on secondary school pupils' ways of thinking about the topic: Positivity and negativity of functions. International Journal for Technology in Mathematics Education, 15(3), 103-117. Retrieved from https://eric.ed.gov/?id=EJ837652

Barton, S. D. (2001). What does the research say about achievement of students who use calculator technologies and those who do no? In P. Bogacki (Ed.), Electronic Proceedings of the Thirteenth Annual International Conference on Technology in Collegiate Mathematics. Retrieved from http://archives.math.utk.edu/ICTCM/ VOL13/C025/paper.pdf

Bowman, E. W. (2018). Using graphing calculators to graph quadratics. ICME-13 Monographs, 399-408. doi:10.1007/978-3-319-76575-4_24

Brown, R. (2010). Does the introduction of the graphics calculator into system-wide examinations lead to change in the types of mathematical skills tested? Educational Studies in Mathematics, 73(2), 181-203. doi:10.1007/s10649-009-9220-2

Burns, M. (2005). Looking at how students reason. Educational Leadership, 63(3), 26-31. Retrieved from http://www.ascd.org/publications/educationalleadership/nov05/vol63/num03/Looking-at-How-Students-Reason.aspx

Cedillo, T. E. (2001). Toward an algebra acquisition support system: A study based on using graphic calculators in the classroom. Mathematical Thinking and Learning, 3(4), 221-259. doi:10.1207/S15327833MTL0304_01

Colburn, A. (2007). Constructivism and conceptual change. The Science Teacher, 74(8), 1418. Retrieved from https://www.questia.com/library/journal/1G1172598337/constructivism-and-conceptual-change-part-ii

Crawford, P., Moseley, D., Nancarrow, M., \& Ward, E. (2018). Calculus challenges: An active learning approach. PRIMUS, 28(6), 616-625. doi:10.1080/10511970.2017.1387630

Dewey, B. L., Singletary, T. J., \& Kinzel, M. T. (2009).Graphing calculator use in algebra teaching. School Science \& Mathematics, 109(7), 383-393. doi:10.1111/j.19498594.2009.tb17869.x 
Ellington, A.J. (2006). The effects of on-CAS graphing calculators on student achievement and attitude levels in mathematics: A meta-analysis. School Science and Mathematics, 106(1), 16. doi:10.1111/j.1949-8594.2006.tb18067.x

Farmer, P. J. (2016). Teacher preparation programs and calculator pedagogy (Unpublished doctoral dissertation). Texas Tech University. Retrieved from https://ttuir.tdl.org/handle/2346/68054

Fennema, E. \& Sherman, J. A. (1976). Fennema-Sherman mathematics attitude scales: Instruments designed to measure attitudes toward the learning of mathematics by females and males. Journal for Research in Mathematics Education, 7(5), 324-326. doi: $10.2307 / 748467$

Foshee, C. M., Elliott, S. N., \& Atkinson, R. K. (2015). Technology-enhanced learning in college mathematics remediation. British Journal of Educational Technology,47(5), 893-905. doi:10.1111/bjet.12285

Francis, J. (2017). The effects of technology on student motivation and engagement in classroom-based learning (Doctoral dissertation, University of New England, 2017). All Theses and Dissertations, 121. Retrieved from https:/ / dune.une.edu/cgi/viewcontent.cgi?article=1120\&context=theses

Handal, B., Cavanagh, M., Wood, L., \& Petocz, P. (2011). Factors leading to the adoption of a learning technology: The case of graphics calculators. Australasian Journal of Educational Technology, 27(2), 343-360. doi:10.14742/ajet.974

Harris, J. L., Al-Bataineh, M. T., \& Al-Bataineh, A. (2016). One-to-one technology and its effect on student academic achievement and motivation. Contemporary Educational Technology 7(4), 368-381. Retrieved from http:/ / www.cedtech.net/articles/74/745.pdf

Hui, W., Hu, P. J. H., Clark, T. H. K., Tam, K. Y., \& Milton, J. (2008). Technology-assisted learning: A longitudinal field study of knowledge category, learning effectiveness and satisfaction in language learning. Journal of Computer Assisted Learning 24(3), 245-259. doi:10.1111/j.1365-2729.2007.00257.x

Kahveci, M. (2010). Students' perceptions to use technology for learning: Measurement integrity of the modified Fennema-Sherman attitudes scales. Turkish Online Journal of Educational Technology,9(1), 185-201. Retrieved from https://www.researchgate.net/publication/230885848_Students'_perceptions_t o_use_technology_for_learning_Measurement_integrity_of_the_modified_Fenne ma-Sherman_attitudes_scales.

Kandemir, M., \& Demirbağ-Keskin, P. (2019). Effect of graphing calculator program supported problem solving instruction on mathematical achievement and attitude. International Journal of Research in Education and Science,5(1), 203-223. Retrieved from https://files.eric.ed.gov/fulltext/EJ1197997.pdf.

Karadeniz, I., \& Thompson, D. R. (2017). Precalculus teachers' perspectives on using graphing calculators: an example from one curriculum. International Journal of Mathematical Education in Science and Technology, 49(1), 1-14. doi:10.1080/0020739x.2017.1334968

King, S., \& Robinson, C. (2012). Do undergraduate students view calculator usage as a proxy for learning with understanding? British Journal of Educational Technology, 43(3), E90-E92. doi:10.1111/j.1467-8535.2012.01289.x

Kwon, H. (2017). Effects of 3D printing and design software on students' overall performance. Journal of STEM Education,18(4). Retrieved from https://www.learntechlib.org/p/181996/.

Leng, H. W. (2011). Using an advanced graphic calculator in the teaching and learning of calculus. International Journal of Mathematical Education in Science and Technology, 42(7), 925-938. doi:10.1080/0020739X.2011.616914 
Martin, A. (2008). Ideas in practice: Graphing calculators in beginning algebra. Journal of Developmental Education, 31(3), 20-37. Retrieved from https:// files.eric.ed.gov/fulltext/EJ832680.pdf

Nzuki, F. (2016). The Role of Situational Context in High School Teachers Use of Graphing Calculator in Mathematics Instruction. International Journal of Online Pedagogy and Course Design,6(2), 29-45. doi:10.4018/ijopcd.2016040103

Olsen, A. K., \& Chernobilsky, E. (2016).The effects of technology on academic motivation and achievement in a middle school mathematics classroom. Proceedings of the National Economics Research Associates. Retrieved from http://digitalcommons.uconn.edu/nera-2016/2

Paquette, G. (2014). Technology-based instructional design: Evolution and major trends. In J. M. Specto, M. D. Merrill, J. Ellen, \& M. J. Bishop (Eds.), Handbook of research on educational communications and technology, $4^{\text {th }}$ ed. (pp. 661-671). New York: Taylor \& Francis Group

Parrot, M. A., \& Leong, K. E., (2018a). Impact of using graphing calculator in problem solving. International Electronic Journal of Mathematics Education,13(3). doi:10.12973/iejme/2704

Parrot, M. S., \& Leong, K. E. (2018b). Teaching and learning calculus in secondary schools with the TI-Nspire. The Malaysian Online Journal of Educational Science,2(1), 27-33. Retrieved from http://mojes.um.edu.my/index.php/MOJES/article/view/12822

Porter, R. C., Ofodile, C., \& Carthon, J. (2015). Redesigning college algebra for success: An analysis of student performance. Georgia Journal of Science,73(2), 5th ser., 153159.

Retrieved

from https:// digitalcommons.gaacademy.org/cgi/viewcontent.cgi?article=1168\&con text $=$ gjs.

Simpson, T. (2002). Dare I oppose constructivist theory? The Educational Forum, 66(4), 347-354. doi:10.1080/00131720208984854

Tan, C., \& Tan, C. (2015).Teaching probability with graphic calculator instructional approach. The Journal of Developing Areas, 49(5), 11-23. doi:10.1353/jda.2015.0061 